\title{
MODELAGEM DA RECARGA HÍDRICA DE ÁGUAS SUBTERRÂNEAS DA BACIA DO RIO UBERABINHA - UBERLÂNDIA - MG
}

\author{
Eleonora Henriques Amorim de Jesus \\ Universidade Federal de Uberlândia - UFU \\ Instituto de Geografia \\ eleonoraamorim@globo.com \\ Michele Paula Da Silva \\ Universidade Federal de Uberlândia - UFU \\ michelly.paula.silva@gmail.com \\ Karina do Valle Marques \\ Universidade Federal de Uberlândia - UFU \\ Faculdade de Medicina \\ karina@ufu.br
}

\begin{abstract}
RESUMO
Nos últimos anos, principalmente no Brasil, os recursos hídricos passaram a ter uma maior visibilidade e utilização devido ao período de desenvolvimento econômico acelerado no país. Para minimizar os impactos sofridos por essas extrações dos recursos hídricos aceleradas, vários instrumentos de gestão vêm sendo desenvolvidos com 0 intuito de apoiar 0 planejamento em nível de bacias hidrográficas. O presente trabalho teve como objetivo realizar um estudo de gestão de águas através da plataforma AQUATOOL com base no modelo EVALHID para modelar a recarga hídrica de água subterrânea na Bacia do Rio Uberabinha durante um período de avaliação de 10 anos (janeiro 2005 a dezembro de 2014). Em relação aos resultados obtidos foi possível perceber que a infiltração e/ou recarga hídrica é influenciada diretamente pelos valores de precipitação, evapotranspiração e escoamento superficial, os meses em que a chuva é intensa a taxa de infiltração também é maior, e o mesmo acontece ao contrário, ou seja, é necessário garantir a preservação/ conversação de todo sistema hidrológico para garantir o abastecimento do subsolo na bacia em questão. Enfim, a aplicação do modelo juntamente com a calibração apresentou resultados satisfatórios nos estudos realizados na Bacia do Rio Uberabinha, podendo vir auxiliar os órgãos gestores desta área na tomada de decisões e planejamentos para manutenção e preservação dos recursos hídricos.
\end{abstract}

Palavras-chave: Modelagem hidrológica. Águas subterrâneas. Ferramenta AQUATOOL. Modelo EVALHID. Rio Uberabinha.

\section{MODELING OF THE UNDERGROUND WATER RECHARGE OF THE UBERABINHA RIVER BASIN - UBERLÂNDIA - MG}

\begin{abstract}
In the last years, mainly in Brazil, the hydric resources got more visibility and use due to the accelerated economic development in the country. To decrease the suffered impacts by accelerated water resources exploitation, many management devices has been developed aiming to support the management and planning of the water resources in level of watersheds. Thus, the present paper had as objective to realize a study of water management. With the use of the platform AQUATOOL based in the model EVALHID to model the hydric recharge of groundwater in the Uberabinha River watershed during the time of assessment of 10 years (January of 2005 to December of 2014). The hydric recharge results found with the use of the model it were possible to identify that the percolation or the water recharge were influenced directly by the values of precipitation, evapotranspiration and superficial water flow, the months that the rain were intense the percolation rate were also bigger, and the same happens in the opposite way. Thus, it is necessary to guarantee the preservation and the conservation of the completely hydrologic system to maintain the water supply for the watershed groundwater. Therefore, the application of this model alongside the calibration process presented satisfactory results in the studies realized in the Uberabinha River watershed, may come support the management public bodies of this area for the hydric resources maintenance.
\end{abstract}

Keywords: Modelagem hidrológica. Águas subterrâneas. Ferramenta AQUATOOL. Modelo EVALHID. Rio Uberabinha.

$\begin{array}{llllll}\text { Caminhos de Geografia } & \text { Uberlândia-MG } & \text { v. 20, n. } 70 & \text { Junho/2019 } & \text { p. 311-330 Página } 311\end{array}$




\section{INTRODUÇÃO}

O subsolo estoca cerca de 10,5 milhões de km3 de água subterrânea doce. Isto representa 97\% dos volumes de água doce líquida existente nos continentes, passíveis de acesso por meios tecnológicos e econômicos. Estas águas podem ser utilizadas para abastecimento das populações, indústrias e atividades agropecuárias devendo-se, para isto, empregar a forma correta de captação (REBOUÇAS et al.,1999). Por isso, a água subterrânea consiste em um recurso natural em destaque não só no Brasil, mas no mundo todo, em virtude do seu grau elevado de importância no requisito social, econômico e ambiental.

Segundo o Censo de 2000 (IBGE, 2003), aproximadamente 60\% da população brasileira é abastecida, para fins domésticos, com água subterrânea, sendo que 6\% se auto abastece das águas de poços rasos, $12 \%$ de nascentes ou fontes e $43 \%$ de poços profundos. Por isso, o número de poços tubulares de água subterrânea em operação do Brasil está estimado em cerca de 300.000, com um número anual de perfurações de aproximadamente 10.000 .

O município de Uberlândia possui uma demanda relativamente grande por água para o abastecimento público e para o desenvolvimento de suas atividades econômicas. Segundo o Instituto Brasileiro de Geografia e Estatística, IBGE (2014), o município possui uma população de 654.681 habitantes, que consome, em média, $13.093 .620 \mathrm{~m}^{3}$ de água/mês (DMAE, 2015), de acordo com esses dados o consumo médio de água por pessoa em Uberlândia é quase o dobro que o recomendado pela Organização das Nações Unidas (ONU). Um uberlandense gasta 200 litros por dia de água, enquanto o valor recomendado pela ONU é de 110 litros/ dia. Além da utilização eventualmente de parte da água subterrânea da Bacia do Rio Uberabinha para o abastecimento dos distritos de Uberlândia, indústrias e atividades agropecuárias da região.

A modelagem matemática consiste na representação do que acontece na natureza a partir de um modelo conceitual, idealizado com base no levantamento e interpretação de dados e observações do sistema real, tendo como objetivo uma melhor compreensão do sistema atual, possibilitando prever situações futuras, algumas vezes passadas, porém sempre buscando direcionar ações de decisão (IRITANI, 1998). Com isso, a aplicação da modelagem com resultados qualitativos e quantitativos em estudos de água subterrânea e em possíveis impactos ambientais vem ganhado destaque na literatura, por demonstrarem resultados atuais e perspectivas futuras em relação ao tema estudado.

Sendo assim, este trabalho teve como objetivo realizar a modelagem da recarga hídrica das águas subterrâneas da bacia hidrográfica do rio Uberabinha com base em aspectos do meio físico natural utilizando os dados climatológicos disponibilizados pela estação da Universidade Federal de Uberlândia (UFU), a fim de promover medidas corretivas e/ou mitigadoras para as áreas avaliadas com um baixo índice de disponibilidade de água.

\section{METODOLOGIA}

\section{CARACTERIZAÇÃO DA ÁREA DE ESTUDO}

O rio Uberabinha é afluente do rio Araguari pela margem esquerda, em Minas Gerais. A sua bacia engloba os municípios de Uberaba, Uberlândia e Tupaciguara, na região do Triângulo Mineiro, drenando uma área de aproximadamente $2.195,08 \mathrm{~km}^{2}$. Possui uma extensão de $142,7 \mathrm{~km}$ e situase entre as coordenadas geográficas de $18^{\circ} 36^{\prime}$ e $19^{\circ} 21^{\prime}$ de latitude sul e entre as coordenadas geográficas de $47^{\circ} 51^{\prime}$ a $48^{\circ} 33^{\prime}$ Oeste (DUARTE e BRITO, 2005; SALLA et al., 2014). (Figura 1). 
FIGURA 1 - Local de estudo- Bacia do Rio Uberabinha.

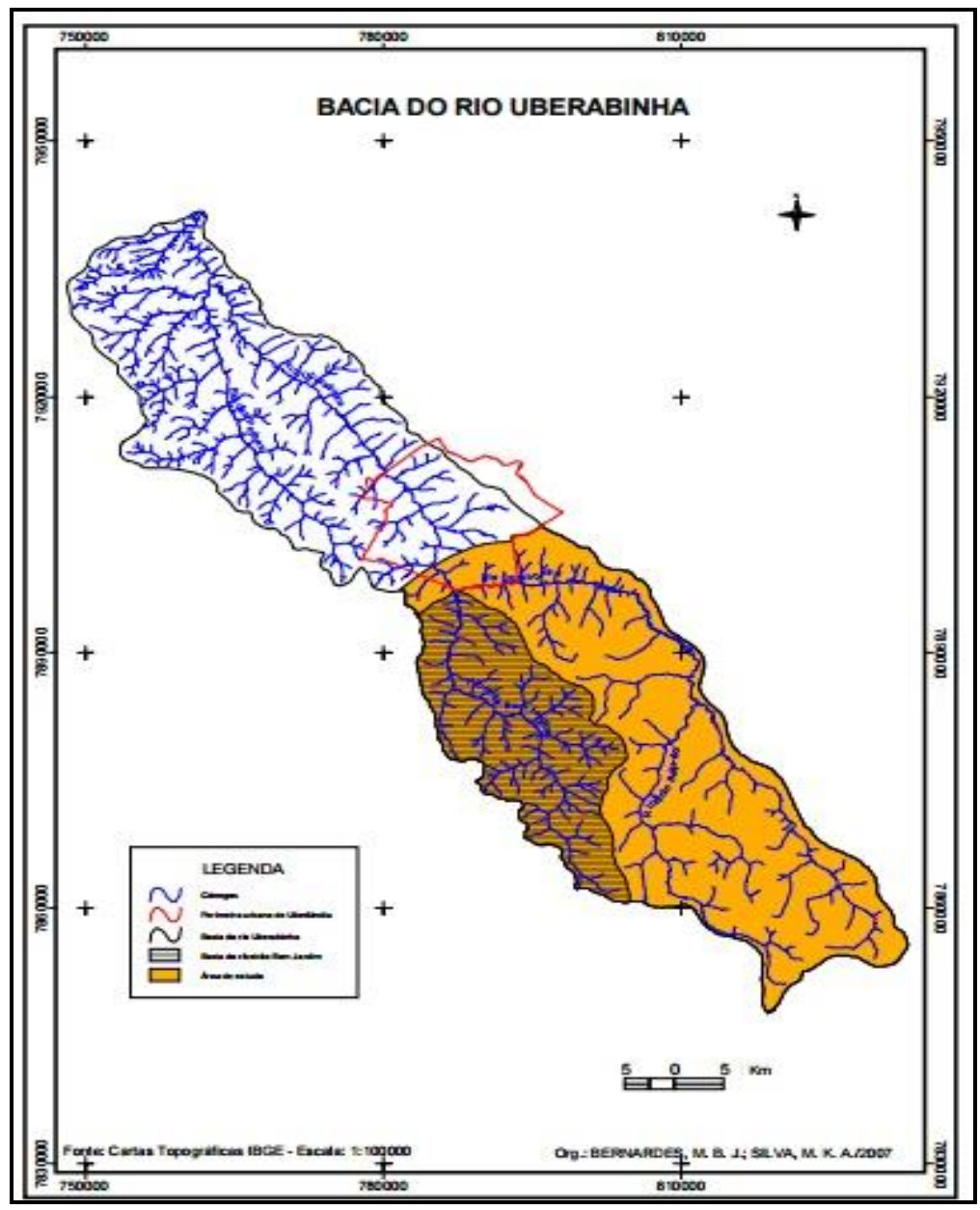

Fonte - Carta Topográfica IBGE- Escala 1: 100 000(2013).

O rio Uberabinha percorre áreas de lavouras, pastagens e reflorestamento, extensas áreas de brejo constituídas de solos úmidos com espessos horizontes de argila branca recoberta de turfa, e longos trechos de matas ciliares que, com sua vegetação rica e variada, oferecem alimento para a fauna, ajudam a preservar a qualidade da água e protegem as margens dos processos erosivos evitando o assoreamento da calha do rio (SANTOS et al. 2017).

\section{PROCEDIMENTOS DO ESTUDO}

Inicialmente foi realizada uma pesquisa bibliográfica para o levantamento de dados e informações sobre a bacia do Rio Uberabinha. Com os dos dados coletados verificou-se como ocorre à distribuição da água na região e a quantidade disponibilizada de água subterrânea semestralmente para toda a população, considerando os meses chuvosos e os de estiagem na cidade.

Outra pesquisa foi realizada posteriormente, os dados climatológicos foram coletados de acordo com a disponibilidade de informações e os dados fluviométricos, mais precisamente vazão também foram coletados para atender as exigências do modelo. Esses dados foram obtidos na estação meteorológica da Universidade Federal de Uberlândia.

Os dados de precipitação, evapotranspiração, temperatura e vazão, foram utilizados para a calibração dos parâmetros e somente após todo este processo foi possível realizar a validação do modelo em relação à recarga hídrica na bacia do Rio Uberabinha.

\section{MODELO CONCEITUAL AQUATOOL}

O AQUATOOL é uma plataforma e/ou ambiente de desenvolvimento de sistemas de apoio à decisão (SSD) para o planejamento e gestão de bacias hidrográficas e sistemas de água. Essa 
ferramenta já foi utilizada por diversos autores (FERREIRA, 2014; SALLA et al. 2014a, NASCIMENTO, 2016)

Para ajudar a análise de vários problemas relacionados com a gestão da água, ele fornece vários recursos de qualidade e quantidade de águas subterrâneas e superficiais, tornando-se assim um ambiente de uma linha de pesquisa em desenvolvimento contínuo, auxiliando de diversas formas a gestão de águas.

A plataforma AQUATOOL conta com vários softwares para o desenvolvimento e aplicação prática do progresso e do novo conhecimento gerado pela gestão dos Recursos Hídricos, os principais modelos disponibilizados gratuitamente são SIMGES, CAUDECO, GESCAL, EVALHID e OPITGES. Detalhes dos modelos descritos em Paredes-Arquila et al. (2011).

Os modelos são softwares livres, ou seja, podem ser livremente baixados e instalados sem uma licença e sem custo de obtenção. A instalação sem licença permite edição e visualização de resultados para os regimes de qualquer tamanho, a plataforma permite ainda o uso de módulos de cálculo para os regimes de dimensões limitadas.

\section{Modelo EvalHid}

O programa de avaliação dos recursos hídricos (EvalHid) é um módulo de software do AQUATOOL disponibilizado para o desenvolvimento de modelos de precipitação-escoamento ou chuva-vazão em bacias e complexos que permite a avaliação dos recursos hídricos (qualidade ou quantidade) em uma ou várias bacias hidrográficas simultaneamente. O módulo consiste de vários tipos de modelos que podem ser escolhidos de acordo com os dados disponíveis para a calibração.

A ferramenta foi desenvolvida por Paredes-Arquiola et al. (2011) e integra seis modelos chuvavazão (HBV, Témez, Sacramento, GR2M, GR4J e AWBM), todos do tipo agregado com aplicação semidistribuída, ou seja, a bacia hidrográfica é dividida em sub-bacias para o procedimento. Nesta nota técnica, em função dos dados hidrológicos disponíveis na região de estudo e do reduzido número de parâmetros a calibrar foi utilizado o modelo HBV para se avaliar a quantidade de água subterrânea disponível no Rio Uberabinha de acordo com a recarga de chuva-vazão.

\section{Modelo HBV}

O modelo HBV está integrado ao EVALHID, trata-se de um modelo computadorizado de captação que converte precipitação e evapotranspiração potencial em vazão num canal ou reservatório, por meio da simulação de processos hidrológicos naturais. Para realizar a calibração os parâmetros devem possuir registros meteorológicos e de vazão em um período de avaliação de três a cinco anos simultâneos.

Este modelo tem sido usado desde 1977 na previsão de vazões em tempo real, na Suécia é considerada a ferramenta de previsão padrão, onde cerca de 50 áreas de captação são monitoradas pelo Serviço nacional de Alarme de Cheias com base no modelo HBV.

O modelo trabalha com escala temporal diária ou mensal e utiliza como dados de entrada, as séries de precipitação, temperatura do ar e evapotranspiração média mensal.

\section{Calibração com os Algoritmos Genéticos (SCE-UA)}

A calibração é o processo em que os parâmetros de modelo são ajustados, de forma que o modelo reproduza o comportamento das variáveis observadas na bacia hidrográfica da forma mais real possível, para isso são necessários dados observados para a calibração, sendo estes dados normalmente as series de vazões observadas em um ou mais locais na bacia em um período estipulado. 
O algoritmo foi no início descrito por Duan et al., (1994), com o intuito de analisar a superfície de resposta de funções objetivo aplicadas a problemas de calibração de modelos hidrológicos chuvavazão devido a calibração automática na maioria das vezes encontrar apenas pontos ótimos locais. Por isso, o SCE-UA é considerado um método baseado na combinação de técnicas de busca aleatória, algoritmos genéticos e otimização local, com êxito na resolução na resolução de problemas não lineares em diversas aplicações de modelos hidrológicos em escala de bacia hidrográfica. O nome SCE é derivado das iniciais de Shuffled Complex Evolution, o que pode ser traduzido por "Evolução de Complexos Misturados" (Diniz, 1999). As letras UA provém de Univesity of Arizona, instituição de origem dos autores do algoritmo.

Basicamente, o algoritmo é responsável por avaliar a quantidade de combinações de valores de parâmetros para encontrar o melhor ajuste entre os dados observados e simulados.

Este ajuste se avalia maximizando o valor médio, ou seja, selecionando os melhores valores encontrados nas funções objetivo descritas nas Equações (1), (2), (3) e (4) (NASH e SUTCLIFF, 1970).

$$
\begin{gathered}
F_{1}=1-\frac{\sum_{t=1}^{n}\left[Q_{\text {sim }}(t)-Q_{o b s}(t)\right]^{2}}{\sum_{t=1}^{n}\left[Q_{o b s}(t)-\overline{\left.Q_{o b s}\right]^{2}}\right.}(1) \\
F_{2}=1-\frac{\sum_{t=1}^{n}\left[\ln \left(Q_{\text {sim }}(t)\right)-\ln \left(Q_{o b s}(t)\right)\right]^{2}}{\sum_{t=1}^{n}\left[\ln \left(Q_{o b s}(t)\right)-\ln \left(\overline{Q_{o b s}}(t)\right)\right]^{2}} \\
F_{3}=\frac{\sum_{t=1}^{n}\left(Q_{\operatorname{sim}}(t)-\overline{Q_{s i m}}\right) \cdot\left(Q_{o b s}(t)-\overline{Q_{o b s}}\right)}{\sqrt{\sum_{t=1}^{n}\left(Q_{\operatorname{sim}}(t)-\overline{Q_{s i m}}\right)^{2} \cdot \sum_{t=1}^{n}\left(Q_{o b s}(t)-\overline{Q_{o b s}}\right)^{2}}} \\
F_{4}=1-\left[\operatorname{máx}\left(\overline{\frac{Q_{\text {sim }}}{Q_{o b s}}} \cdot \frac{\overline{Q_{o b s}}}{Q_{\operatorname{sim}}}\right)-1\right]^{2}
\end{gathered}
$$

Onde: $Q \operatorname{sim}(t)$ e $Q o b s(t)$ são respectivamente as vazões simuladas e observadas no determinado intervalo de tempo $t$ (neste caso adotado como 1 (um) para se obter uma maior precisão nos resultados); $n$ é o número de meses da calibração e a barra alta nas vazões indica o valor médio. Ainda na equação, o F1 é o coeficiente de eficiência de Nash-Sutcliffe (NS), onde se tem a relação entre os volumes de vazões calculadas e obtidas; F2 é o coeficiente de eficiência de Nash- Sutcliffe da transformação logarítmica da vazão (In NS); F3 é o coeficiente de correlação de Pearson; F4 é uma medida da simetria do ajuste entre a simulação média e a observação média, equações estas padronizadas na calibração manual SCE-UA.

\section{PARÂMETROS CLIMATOLÓGICOS E FLUVIOMÉTRICOS}

Para a validação do modelo foi necessário obter alguns parâmetros climatológicos da bacia em estudo, esses dados foram disponibilizados pelo Laboratório de Climatologia da Universidade Federal de Uberlândia (UFU) de acordo com o período estabelecido, além disso foi necessário obter os dados fluviométricos de vazão no local, estes foram disponibilizados pela ANA através do monitoramento do poço na Fazenda Letreiro (Cód. 60381000) localizada na região de Uberlândia conforme Figura 2. 
FIGURA 2 - Localização do Poço de Monitoramento Fazenda Letreiro (Cód. 60381000).

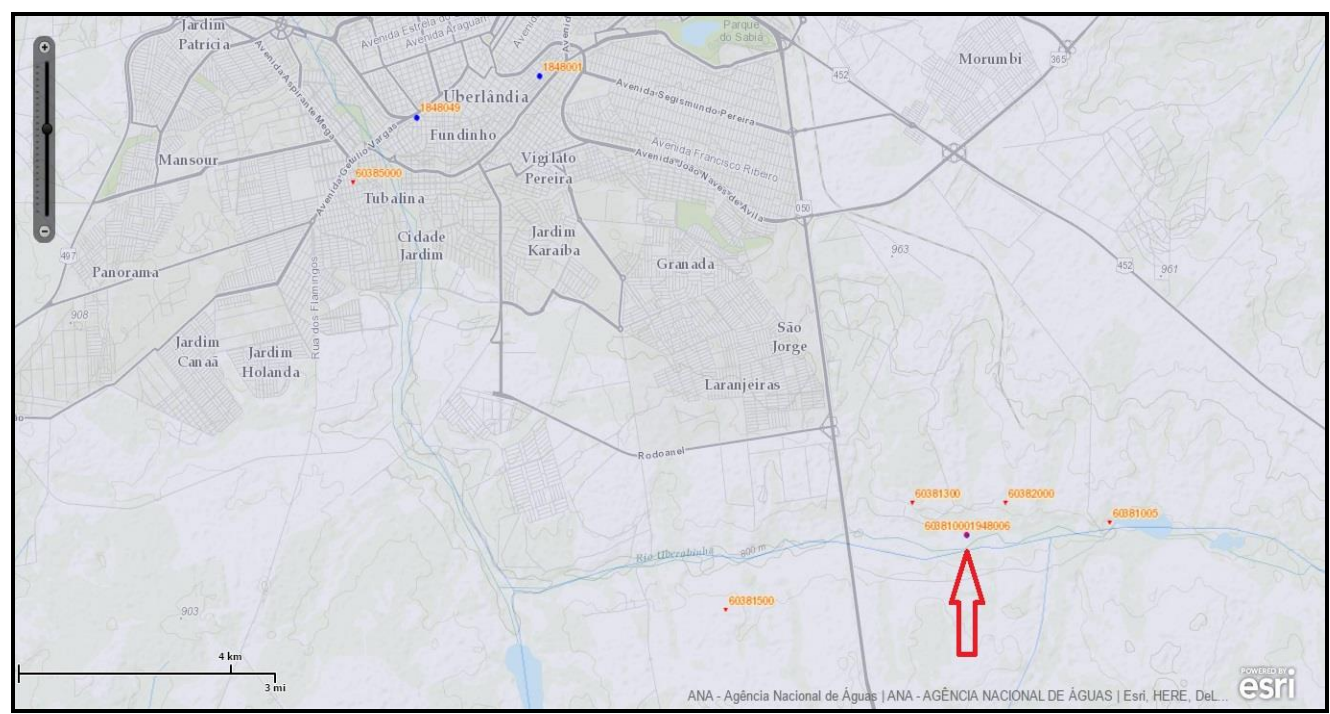

Fonte - ANA (2015)

Com base em estudos realizados sobre o modelo EvalHid e para se alcançar resultados mais precisos do modelo, estipulou-se um período de 10 anos para obtenção dos parâmetros, ou seja, foram coletados dados de precipitação, temperatura e vazão de janeiro de 2005 a dezembro de 2014.

Entende-se por precipitação a água proveniente do vapor de água da atmosfera depositada na superfície sob qualquer forma: chuva, granizo, neblina, neve, orvalho ou geada. Sendo assim, as precipitações acontecem no momento em que o vapor de água que se encontra nas nuvens se congela em razão da altitude, a partir dessa condensação desloca-se em direção à superfície terrestre em estado líquido ou sólido.

O conceito de temperatura se refere a uma grandeza física diretamente relacionada ao estado de movimento ou agitação das partículas que compõe a superfície terrestre. Sendo assim, a temperatura está diretamente ligada à umidade do ar, e as duas variam, ou sejam quando o ar está muito seco, a umidade do ar está muito baixa, já quando o ar está mais úmido, a umidade está mais alta. Para medir se devem usar os termômetros, elementos chave para ter uma ideia realista da temperatura dos ambientes.

Basicamente, vazão é o volume de água que passa por uma seção de um rio ou canal durante um determinado tempo, ou seja, é a infiltração de água nas camadas das bacias em virtude da precipitação no local. Este parâmetro é a principal grandeza que caracteriza um escoamento superficial ou subterrâneo nas bacias.

A evapotranspiração é definida como sendo o processo simultâneo de transferência de água para a atmosfera por evaporação da água do solo e plantas, ou seja, é qualquer processo pelo qual a água da planta ou do solo passa ao estado de vaporem uma dada condição climática. Para validação do modelo foi necessário utilizar os dados de Evapotranspiração Potencial (ETP) da região de Uberlândia, que nada mais é do que a quantidade de água transferida à atmosfera por transpiração e/ou evaporação, na unidade de tempo de uma superfície extensa completamente coberta por vegetação de porte baixo e bem suprida de água.

Diante da dificuldade de se obter o parâmetro de evapotranspiração em relação à Bacia do Rio Uberabinha, foi necessário utilizar-se de alguns cálculos realizados em outras metodologias, com o auxílio dos dados já coletados no Laboratório de Climatologia a equação utilizada para se obter os dados de evapotranspiração desejado foi a de Jensen e Haise [Tucci et al.,(2004)], um método baseado basicamente na radiação e temperatura, que ultimamente tem fornecido resultados razoáveis em diferentes condições climáticas, sendo assim a Equação 5 que representa o Método de Jensen e Haise para evapotranspiração, é dada por:

$$
\mathrm{ETP}=(0,025 \mathrm{~T}+0,08) \times \frac{\mathrm{G}}{59}
$$


Onde, ETP é a evapotranspiração potencial ( $\mathrm{mm} / \mathrm{dia})$; T é a temperatura do $\operatorname{ar}\left({ }^{\circ} \mathrm{C}\right)$ e $\mathrm{G}$ a radiação solar de onda curta (cal/cm2), especificada no Quadro 1.

Quadro 1 - Radiação Solar de onda Curta $\left(\mathrm{cal} / \mathrm{cm}^{2}\right)$ para a latitude $7^{\circ}$ Sul.

\begin{tabular}{cc}
\hline Meses & G (Radiação) \\
\hline Janeiro & 427,34 \\
Fevereiro & 453,14 \\
Março & 436,80 \\
Abril & 460,88 \\
Maio & 475,49 \\
Junho & 447,98 \\
Julho & 466,04 \\
Agosto & 516,77 \\
Setembro & 538,26 \\
Outubro & 542,56 \\
Novembro & 484,95 \\
Dezembro & 458,30 \\
\hline Fonte - Jensen \& Haise [Tucci et al., (2004)].
\end{tabular}

Dessa forma, para se obter dados mais próximos a realidade do local, foi calculada a evapotranspiração mensalmente para cada ano, ou seja, de janeiro de 2005 a dezembro de 2014.

\section{RESULTADOS E DISCUSSÃO}

\section{DADOS DE ENTRADA}

Os dados temporais de entrada para a Bacia do Rio Uberabinha incluem precipitação, evapotranspiração potencial, precipitação e vazão. No presente trabalho utilizou-se uma escala mensal, com um período único em função da disponibilidade de dados históricos, cujo máximo para o estudo foi estipulado em 10 anos (de janeiro de 2015 a dezembro de 2014).

A Figura 3 indica os resultados obtidos através das médias registradas por meses sobre o parâmetro de precipitação no local de estudo durante 10 anos.

FIGURA 3 - Média Mensal de Precipitação em mm.

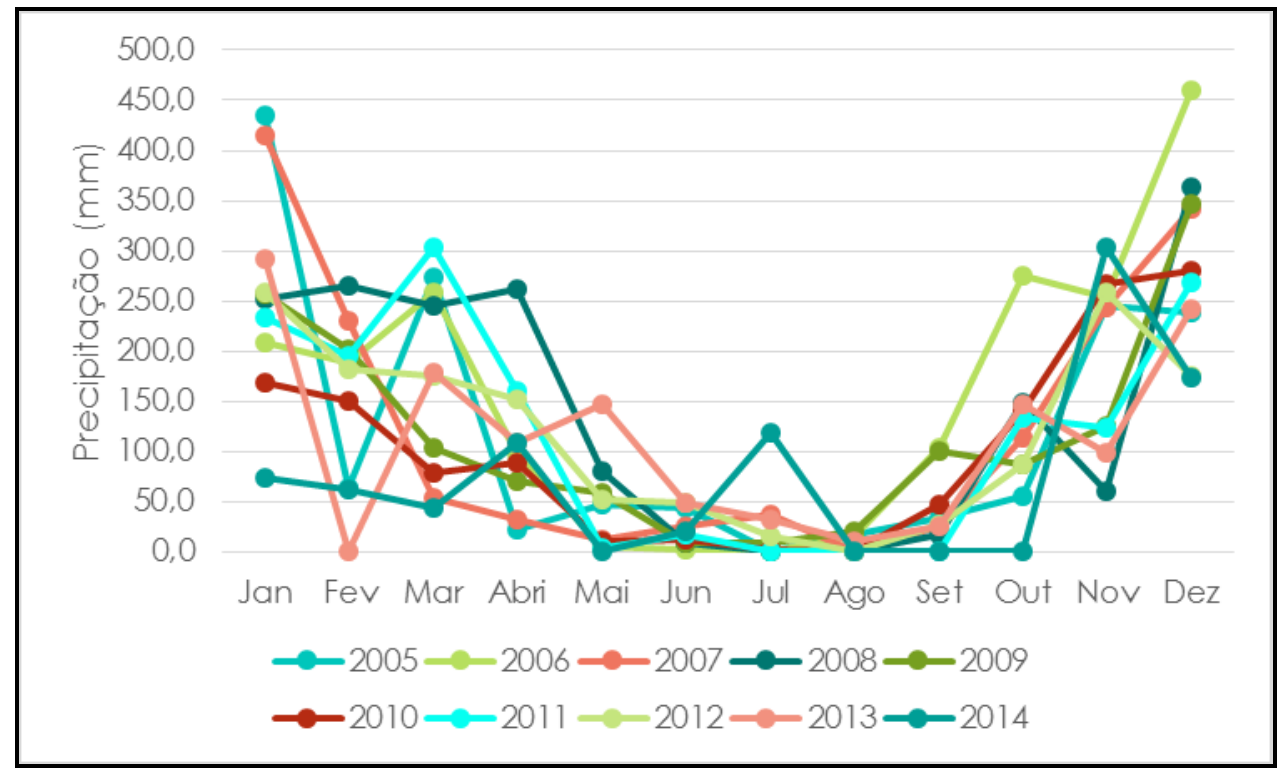

Fonte - Laboratório de Climatologia da UFU (2015). 
De acordo com as médias encontradas é possível perceber que nos últimos três anos a precipitação na região diminuiu significativamente em relação aos anos anteriores, destaca-se o ano de 2014 (Figura 4) onde o índice foi inferior a 1000 mm no ano, foi a primeira vez em 10 anos em que essa situação ocorreu.

FIGURA 4 - Média anual em Precipitação (mm).

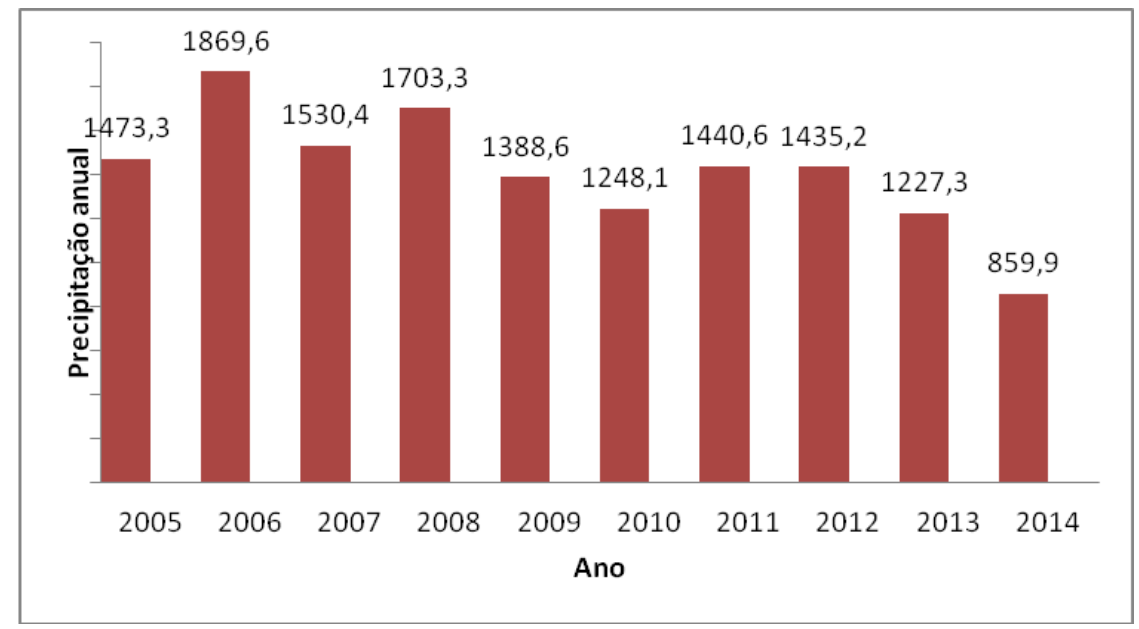

Fonte - Laboratório de Climatologia da UFU (2015).

Diversos são os fatores que impactam os resultados, o aumento da região industrial, a falta de uma conservação das áreas de preservação principalmente na região mais próxima ao Rio Uberabinha, além dos efeitos causados na região Sudeste pelo El Niño, fenômeno este que aquece as águas dos oceanos principalmente o Pacifico interferindo diretamente no padrão de chuvas e temperaturas não só da região como em diversos locais no planeta. A crise de água por falta de chuva no ano de 2014 foi vivenciada por todos no Brasil, além disso, outros fatores meteorológicos também influenciaram, tal como o crescimento da demanda e falta de planejamento hidrológico (NOBRE et al., 2015)

A Figura 5 destaca os resultados encontrados das médias mensais sobre os dados coletados de temperatura na região durante 10 anos.

FIGURA 5 - Média mensal de Temperatura do $\operatorname{Ar}$ em ${ }^{\circ} \mathrm{C}$.

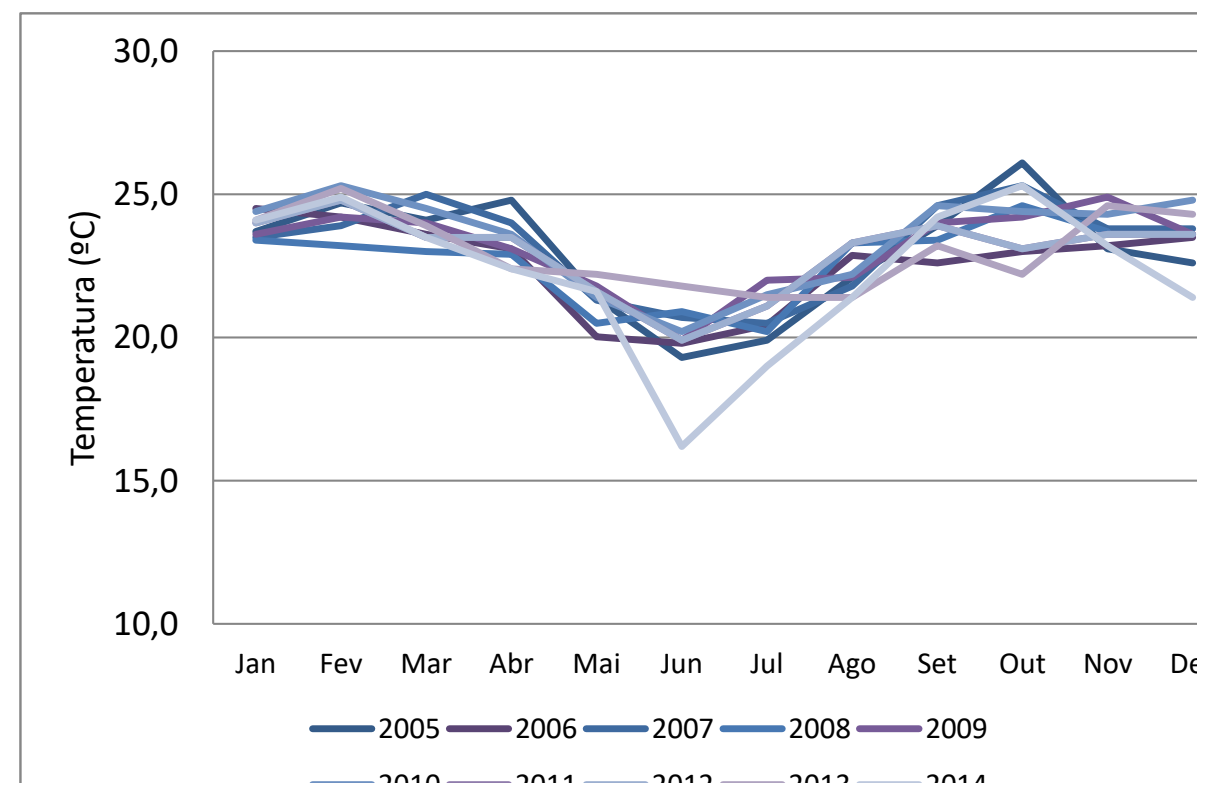

Fonte - Laboratório de Climatologia da UFU (2015). 
Devido à localização da região a temperatura conforme demonstra o gráfico não teve muita alteração durante cada mês dos anos avaliados. Cercada pela vegetação do Cerrado, a região da Bacia do Rio Uberabinha possui os meses de outubro, novembro e dezembro com maiores médias térmicas, ou seja, mais quentes e os meses de maio, junho e julho com temperaturas mais baixas, todo este processo interfere no resultado final de cada ano em relação a temperatura, que influencia diretamente na região, além disso a topografia é determinante na variação espacial da temperatura, visto que os municípios que integram a Bacia do Rio Uberabinha estão localizados em altitudes mais baixas, fazendo com que se tenha temperaturas elevadas durante o verão.

A Figura 6 indica os valores coletados de vazão através da plataforma ANA, no poço de monitoramento de dados fluviométricos de cód. 60381000 , durante o período estipulado.

FIGURA 6 - Média mensal de Vazão em $\mathrm{m}^{3} \mathrm{x} \mathrm{s}^{-1}$.

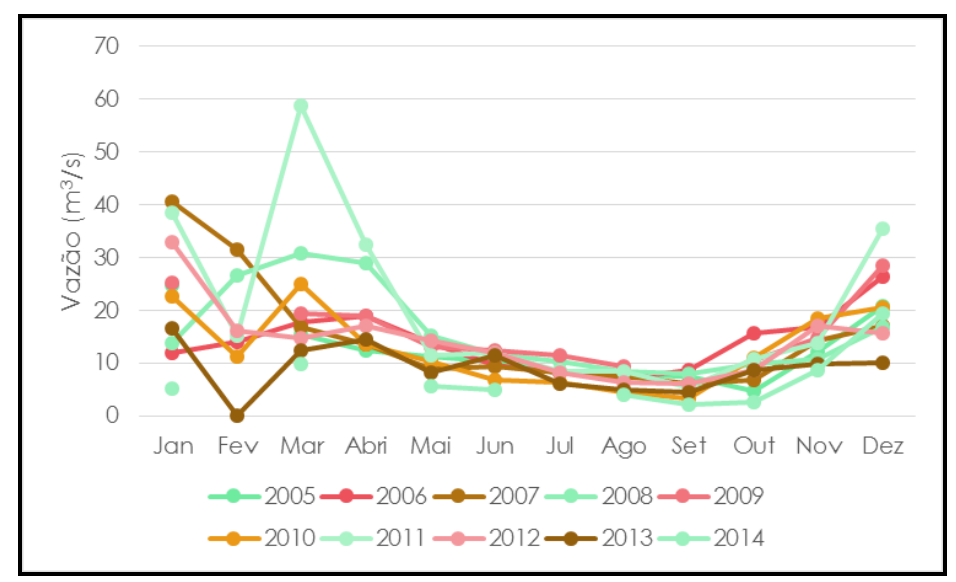

Fonte - ANA (2015)

A vazão está diretamente relacionada com a precipitação, evapotranspiração e até mesmo a temperatura, todos estes parâmetros alteram de certa forma o resultado final do escoamento da água superficial ou subterrânea. De acordo com o gráfico nota-se uma grande variação na vazão durante o período analisado, um exemplo disso pode ser destacado em fevereiro de 2013 onde o resultado encontrado foi praticamente nulo, mês e ano onde o valor de precipitação também alcançou o seu menor valor, o contrário acontece em março de 2011 onde a vazão chega ao seu maior valor juntamente com a precipitação que obteve média acima de $300 \mathrm{~mm}$ no mesmo período.

Por fim, a Figura 7 indica os resultados das médias mensais encontradas nos cálculos realizados para obtenção da evapotranspiração mensal durante os 10 anos estipulados.

FIGURA 7 - Média Mensal de Evapotranspiração em $\mathrm{mm}^{3}$.

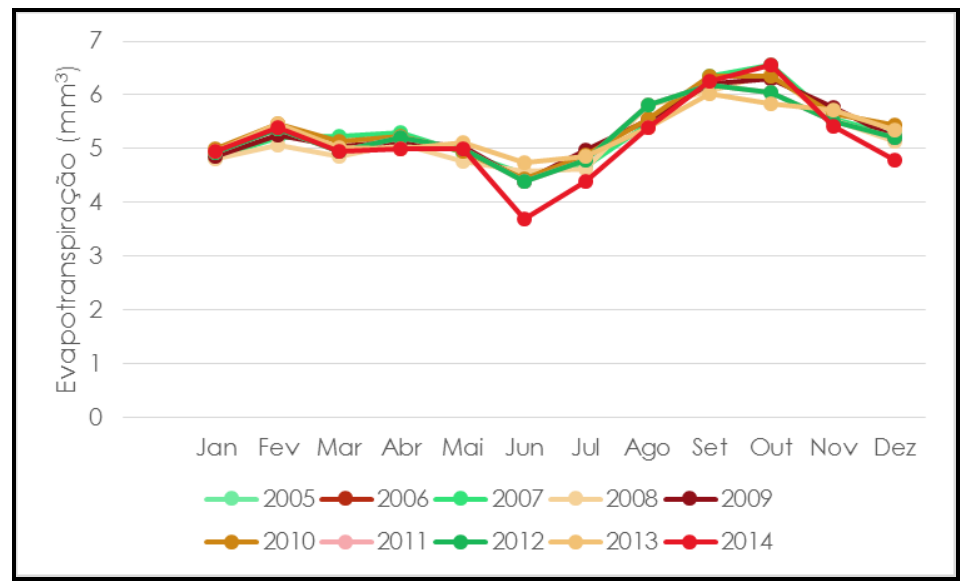

Fonte - Acervo do autor (2015).

$\begin{array}{llllll}\text { Caminhos de Geografia } & \text { Uberlândia-MG } & \text { v. 20, n. } 70 & \text { Jun/2019 } & \text { p. 311-330 } & \text { Página } 319\end{array}$


Nota-se na Figura 4, que ano de 2014 houve uma diminuição de chuvas na região. Além disso, a evapotranspiração também foi menor comparando-se com os anos anteriores. A evapotranspiração é influenciada diariamente por parâmetros meteorológicos como: radiação solar, vento, temperatura do ar, déficit de pressão de vapor, ela é grandemente afetada pelo tipo de cultura, porcentagem de cobertura do solo e disponibilidade de água no solo. A evaporação somente ocorrerá se existir água disponível, a disponibilidade de água é o fator limitante principal de todo o processo, por isso existe uma variação, as vezes mínima, mas existe em relação a todos os parâmetros dependendo do mês.

Ao final, a média de todos os meses resulta a disponibilidade tanto de água quanto de outros parâmetros em cada ano, um exemplo vivenciado foi no ano de 2014 onde a região do Triangulo Mineiro sofreu com a crise hídrica, prova disso são os índices de precipitação e evapotranspiração terem alcançados os menores índices durante os 10 anos analisados (Figuras 4 e 8).

FIGURA 8 - Média Anual de Evapotranspiração em mm³.

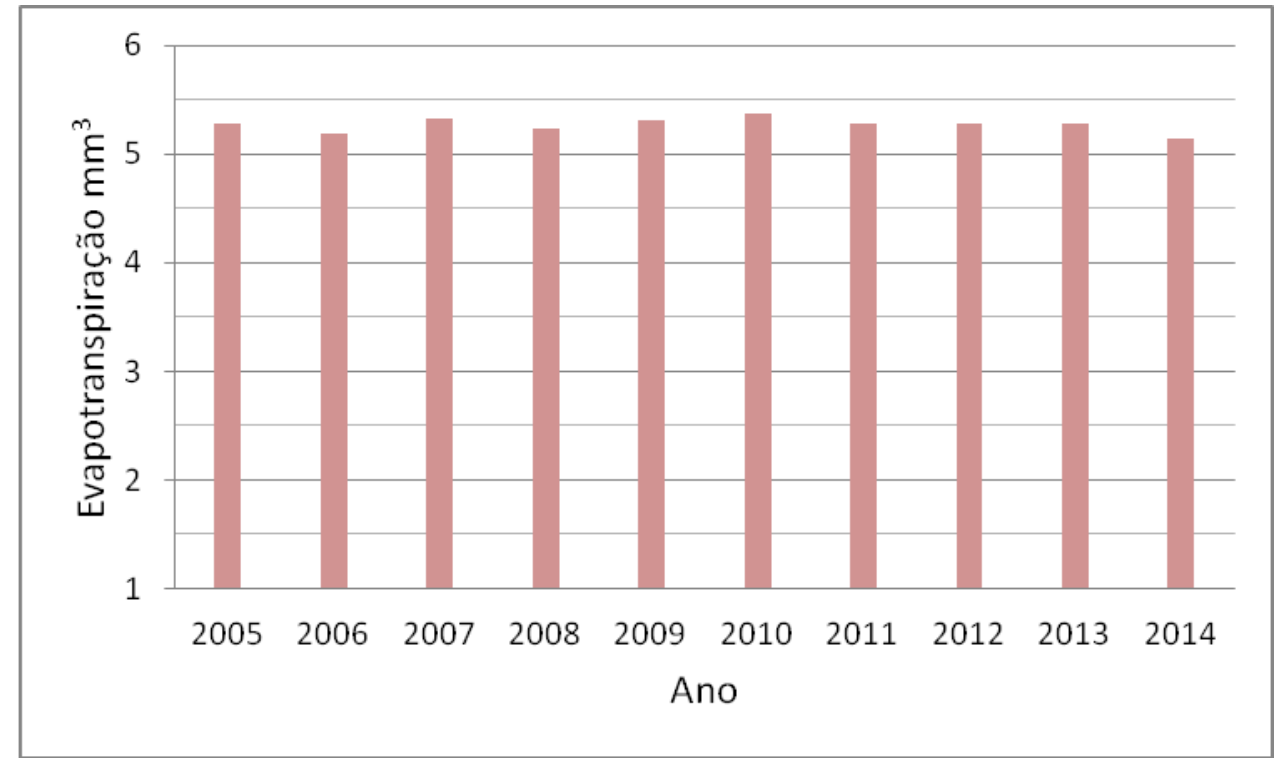

Fonte - Laboratório de Climatologia da UFU (2015).

\section{CALIBRAÇÃO}

Neste trabalho os parâmetros climatológicos e fluviométrico foram calibrados manualmente através do algoritmo evolutivo SCE-UA.

* $\underline{\beta}$ = Parâmetro de ajuste do modelo;

* $\underline{F C}$ = Máxima capacidade de armazenamento do solo;

* $\underline{\mathrm{PWP}}=$ Parâmetro de saturação do solo;

* Lmáx = Limite máximo de fluxo subsuperficial;

* $\underline{\mathrm{K} 0}=$ Coeficiente de escoamento superficial;

* $\underline{\mathrm{K} 1}$ = Coeficiente de escoamento subsuperficial;

* $\underline{\mathrm{K} 2}$ = Coeficiente de escoamento de base;

* Kperc $=$ Coeficiente de percolação.

Pela robustez e simplicidade, todos os parâmetros foram calibrados manualmente, este ajuste é realizado por tentativa e erro, ou seja, cada parâmetro recebe diversos valores e então é realizada repetidas execuções do modelo assim como análises dos resultados. A cada tentativa os valores de vazões mínimas, volume, forma do hidrograma, fator de correção e tempo são analisados. 
Os valores de cada parâmetro assim como os respectivos valores de vazão observada e simulada para cada mês durante os 10 anos são apresentados no Apêndice $A$ e os parâmetros calibrados manualmente pelo algoritmo SCE-UA assim como o valor da função Fmédia estão disponibilizados no Quadro 2 abaixo.

QUADRO 2 - Parâmetros calibrados e valores da Fmédia obtidos pelo algoritmo evolutivo de calibração SCEUA.

\begin{tabular}{cc}
\hline Modelo HBV & \\
\hline$H_{\text {máx }}$ & 450,45 \\
B & 1,56 \\
PWP & 423,89 \\
Lmáx & 100,00 \\
K$_{0}$ & 0,076 \\
$\mathrm{~K}_{1}$ & 0,01577 \\
$\mathrm{~K}_{2}$ & 0,000023 \\
Kperc & 0,1409 \\
Fmédia & 0,42 \\
\hline
\end{tabular}

Fonte - Acervo do autor (2015).

A partir da aplicação inicial já descrita, os valores dos parâmetros foram refinados de forma a melhorar o desempenho do modelo e o ajuste com os dados observados, esse refinamento foi realizado através da ferramenta Solver, trata-se de um comando específico do Excel onde se localiza um valor ideal de (máximo ou mínimo) para uma fórmula em uma célula, ou seja, através do Solver ocorre o ajuste dos valores nas células variáveis de decisão para satisfazer os limites nas células de restrição e produzir o resultado desejado para a célula do objetivo. A Figura 9 apresenta os valores encontrados entre os parâmetros simulados e os observados obtidos através da calibração manual e refinamento no Solver.

FIGURA 9 - Comparação entre os dados simulados e observados após a calibração.

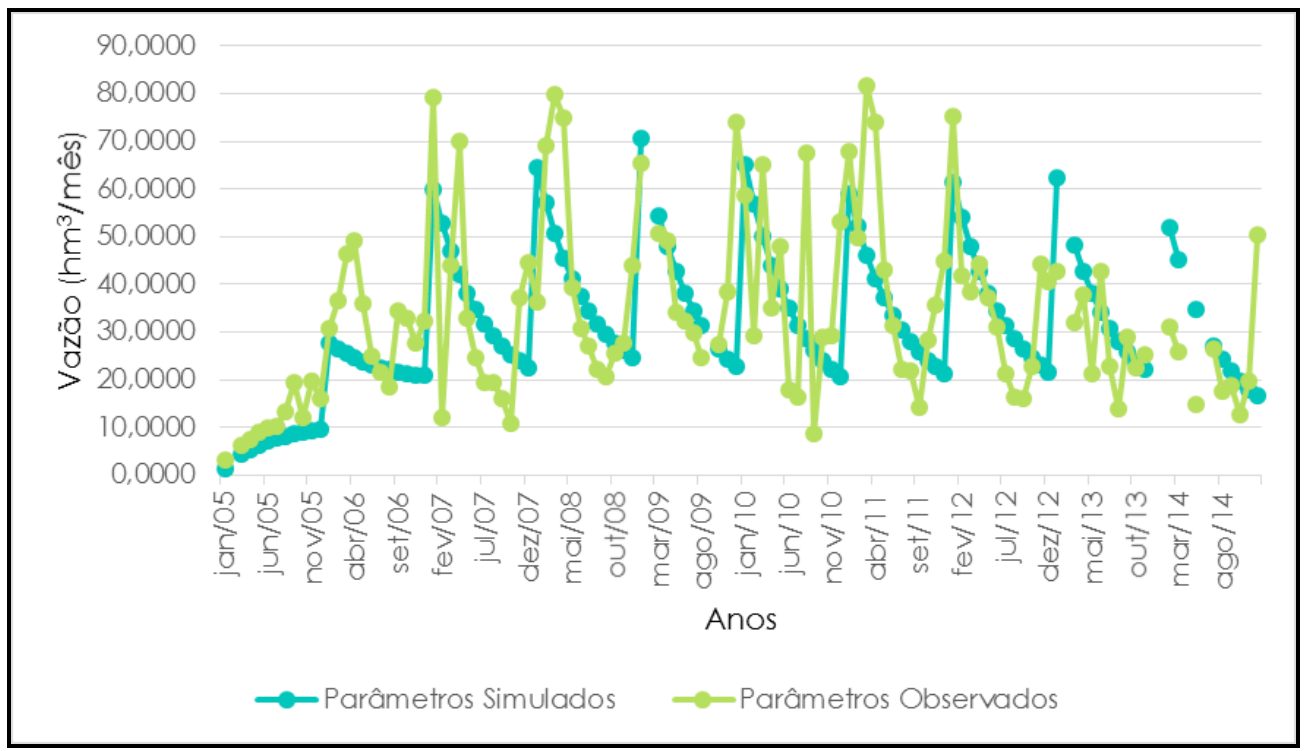

Fonte - Acervo do autor (2015).

Os resultados da calibração dos parâmetros através do método utilizado indicam que os mesmos possuem classificação satisfatória durante o período analisado, isto porque alcançou em seu total uma função Fmédia de 0,42 ocasionando assim um melhor ajuste entre os valores simulados e observados de vazão. 
Por falta de literaturas para a comparação de resultados em níveis de águas subterrâneas, o valor obtido na calibração manual é considerado aceitável para o estudo em si. Um fator que contribui para esta consideração é justamente pela discrepância entre os valores dos parâmetros calibrados pelos modelos com esta finalidade, isso porque se devem levar em consideração as diversas características das bacias hidrográficas estudadas, tais como uso e ocupação do solo, declividade do solo, forma da bacia hidrográfica, configuração da rede de drenagem natural e etc.

Valores aproximados a este foram observados por Costa (2015), onde o mesmo utilizou o modelo para calibração da vazão no Rio Uberaba, obtendo assim um valor de função Fmédia de 0,64 e por Salla et al., (2015), que utilizou o mesmo modelo para simulação de vazões no alto curso do rio Araguari, onde os autores obtiveram valores da função Fmédia variando de 0,602 a 0,767 para o modelo HBV.

\section{VALIDAÇÃO DO MODELO}

De acordo com as informações já citadas, os valores simulados e obtidos de vazão tiveram resultados satisfatórios, ou seja, valores aproximados uns aos outros, todo este processo só foi obtido através da calibração e refinamento do Solver. Como a vazão é diretamente proporcional aos valores de precipitação e evapotranspiração, entende-se que estes dois parâmetros também obtiveram valores aceitáveis em relação ao simulado no modelo EVALHID.

Diante dessas constatações foi possível avaliar a taxa de infiltração durante o período estudado com o auxílio da validação do modelo, dessa forma cada parâmetro (precipitação, evapotranspiração e escoamento superficial) foi comparado individualmente com a infiltração na Bacia do Rio Uberabinha.

A Figura 10 indica a comparação entre infiltração e escoamento superficial (aportacion) no Rio Uberabinha (denominado Subcuenca_P1).

FIGURA 10 - Comparação entre parâmetros de infiltração e escoamento superficial simulados.

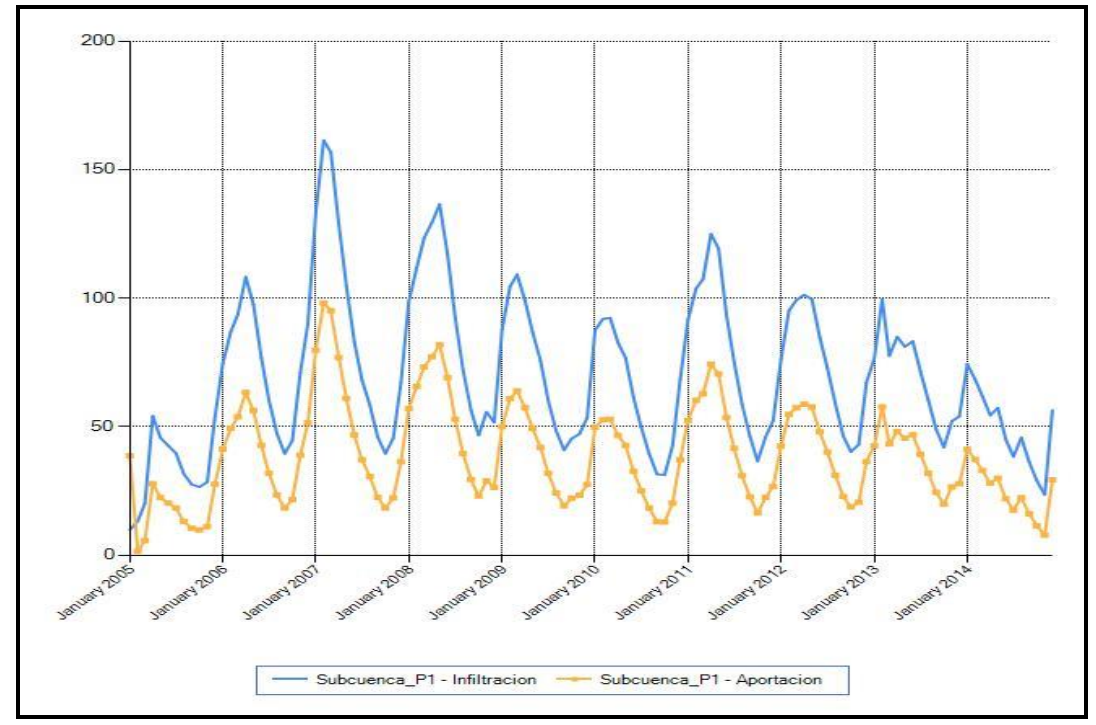

Fonte - Acervo do Autor (2015).

Como já eram esperados os valores de infiltração são maiores do que o de percolação durante todo o período analisado, quando a chuva atinge a área, parte de suas águas é interceptada pela vegetação ocasionando a evapotranspiração e o restante atinge a superfície do solo, neste caso parte se infiltra e o restante escoa pela superfície do terreno, nos meses de maior infiltração como em Maio de 2006 e Março de 2007 o índice de escoamento também foi o maior, isso porque neste período o índice de precipitação foi alto e consequentemente resultou nos maiores valores simulados.

A Figura 11 destaca a comparação de dados de infiltração e evapotranspiração na bacia do Rio Uberabinha durante o período avaliado. 
FIGURA 11 - Comparação entre parâmetros de infiltração e evapotranspiração.

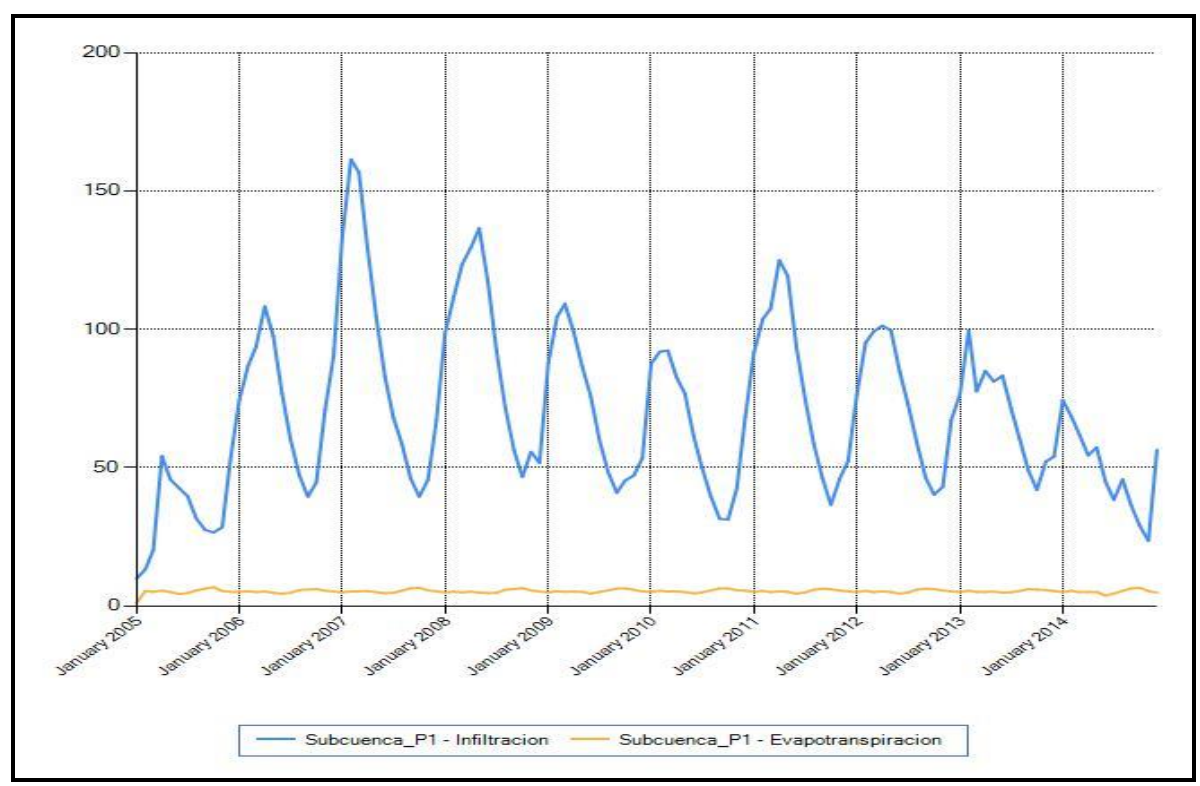

Fonte - Acervo do autor (2015).

A evapotranspiração durante todo o período simulado assim como o observado não sofre muita alteração como ocorre com a infiltração, no entanto é possível perceber que durante os meses onde a evapotranspiração foi maior como, por exemplo, Outubro de $2014\left(6,55 \mathrm{~mm}^{3}\right)$ o índice de infiltração foi menor, isso porque como já foi dito, parte da água precipitada evapora, parte infiltra e parte se escoa.

A quantidade evaporada durante as chuvas intensas é desprezível em relação ao total precipitado durante o período de estudo. No entanto a água ao penetrar no solo reabastece os aquíferos subterrâneos que dependem as vazões dos cursos de água nos períodos de estiagem na região.

Por fim, a Figura 12 indica os valores simulados de infiltração e compara com os de precipitação liquida durante o período estipulado.

FIGURA 12 - Comparação entre parâmetros de infiltração e precipitação líquida.

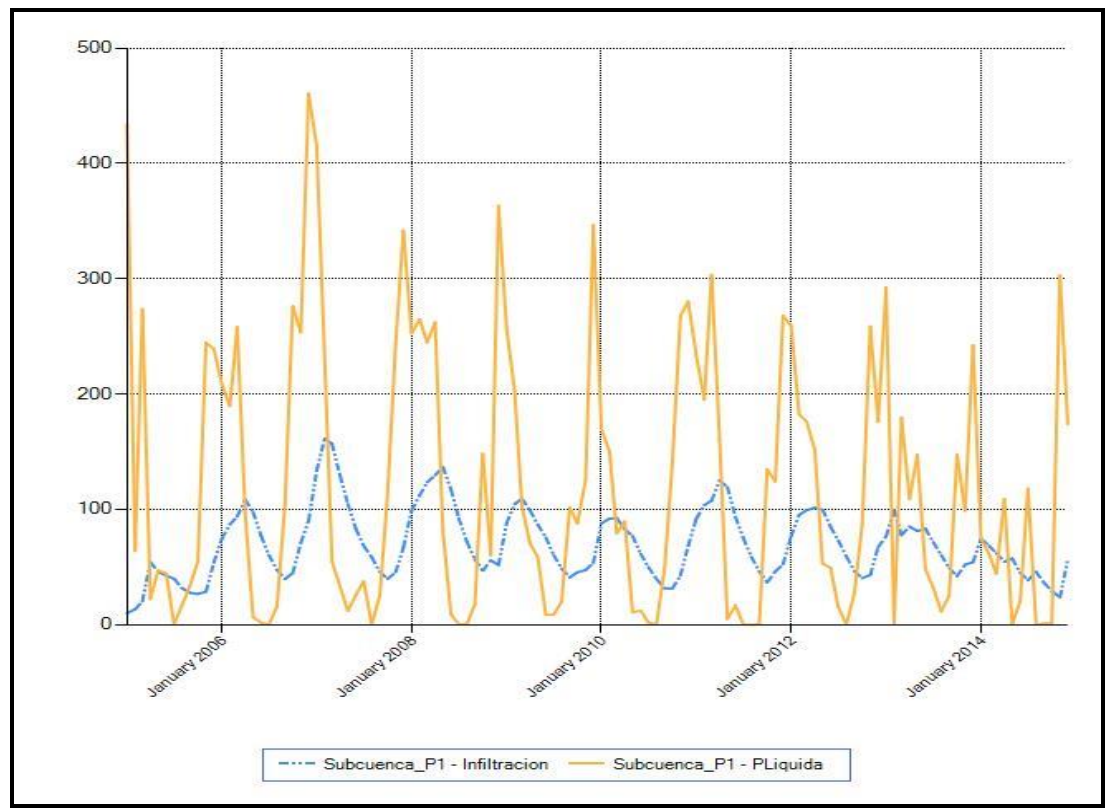

Fonte - Acervo do autor (2015). 
Da mesma forma como os parâmetros anteriores, a precipitação está ligada a taxa de infiltração que ocorre na área de estudo, os meses com maiores índices de precipitação como janeiro de 2007 $(415 \mathrm{~mm})$ resultou-se no período com maior índice de infiltração, o mesmo ocorre em situação contrária, no mês de setembro de 2014 a precipitação apresentou um valor de 0,8 mm caracterizando assim a baixa taxa de infiltração no mesmo período.

\section{CONSIDERAÇÕES FINAIS}

Concluiu-se que o estudo da recarga hídrica no Rio Uberabinha é fundamental para o planejamento e gestão não apenas da bacia em si, mas também para todo o recurso hídrico da região, visto que com essa aplicação abre-se um leque de oportunidades para se realizar a uma melhor gestão da área assim como da disponibilidade de água subterrânea.

Neste trabalho a ferramenta EVALHID, juntamente com o algoritmo evolutivo de calibração SCE-UA e o Solver, apresentaram resultados satisfatórios a partir do modelo HBV, onde através dos mesmos é possível destacar a importância em se preservar o ciclo hidrológico de toda a região estudada.

Deve-se dar mais atenção a conservação das Áreas de Preservação Permanente (APP's) na região, assumindo um novo modelo de gestão das águas e de drenagem urbana, que se regulariza e tenta resgatar em partes o processo natural do ciclo hidrológico, isto porque todos os parâmetros avaliados são influenciados diretamente por este ciclo.

Através de uma gestão mais criteriosa dos recursos hídricos do Rio Uberabinha é possível obter mais dados climatológicos e fluviométricos do mesmo, isso porque uma das maiores dificuldades durante o trabalho foi a parte de dados obtenção de dados do Rio em especifico, justamente por este motivo teve-se que definir um período máximo de 10 anos para coleta dos mesmos, felizmente diversas análises e controles são feitos com as bacias da região, mas a do Rio Uberabinha em si, ainda é muito pouco estudada e todo este processo deve ser revisado, visto que a bacia é responsável por abastecer as cidades de Uberlândia, Martinésia, Cruzeiro dos Peixotos entre outros.

A falta de literatura sobre recarga e/ou disponibilidade de água subterrânea também foi uma das dificuldades encontradas durante todo o trabalho, tema como este se deve ganhar mais espaço dentro de Conferências e Universidade, uma vez em que o país vivenciou a alguns anos uma das maiores crises hídricas da história e um dos métodos mais utilizados durante este período foi a extração de água subterrânea, principalmente nos estados de São Paulo e Minas Gerais.

Recomenda-se prosseguir com os estudos aqui iniciados e com base em mais dados aumentar a demanda de avaliação, levantar pontos de extração da região e verificar a disponibilidade naqueles locais em especifico, realizar monitoramento de qualidade da água subterrânea uma vez que ela é extraída para agricultura e em alguns casos até consumo animal, entre outras pesquisas para se colaborar no monitoramento dessas práticas na região.

Por fim, de uma forma geral, a ferramenta AQUATOOL em junção com o modelo EVALHID atendeu as necessidades deste trabalho quanto à análise de infiltração e/ou recarga hídrica de água subterrânea no Rio Uberabinha, com o auxílio da calibração manual SCE-UA.

Um aspecto que merece ser destacado sobre o modelo é sobre a praticidade em se manusear - EVALHID e a maioria dos modelos disponibilizados pela ferramenta, todos possuem manual técnico e de usuário para auxiliar no entendimento dos mesmos. Por isso, é necessário investir mais em pesquisas para os aspectos quantitativos e qualitativos de água subterrânea na região.

\section{REFERÊNCIAS}

AQUATOOL. Disponível em: <http://www.upv.es/aquatool/es/evalhid_es.html>. Acesso em 28 set. 2015

$\begin{array}{llllll}\text { Caminhos de Geografia } & \text { Uberlândia-MG } & \text { v. 20, n. } 70 & \text { Jun/2019 } & \text { p. 311-330 } & \text { Página } 324\end{array}$


BRASIL. IBGE. Censo demográfico, 2000. Disponível em: <www.ibge.gov.br>. Acesso em 28 set. 2015.

IBGE. Estimativas populacionais dos municípios em 2014. Disponível em: https://agenciadenoticias.ibge.gov.br/agencia-sala-de-imprensa/2013-agencia-denoticias/releases/14659-asi-ibge-divulga-as-estimativas-populacionais-dos-municipios-em2014. Acesso em 28 set. 2015

COSTA, E.S. Estudo de otimização do aproveitamento hídrico superficial no alto curso do rio Uberaba, UPGRH GD8. Dissertação (Mestrado em Engenharia Civil), Faculdade de Engenharia Civil, UFU, 172 p, 2015.

DINIZ, L. S. Calibração de modelos hidrológicos. In: Galvão, C. O.; Valença, M. J. S. 1999 Sistemas inteligentes. Porto Alegre: Editora da Universidade da UFRGS - ABRH, 1999.

DUAN, Q.; SOROOSHIAN, S.; GUPTA, V. Optimal use of the SCE - UA global optimization method for calibrating watershed models. Journal of Hydrology, v. 158 p. 265-284, 1994. https://doi.org/10.1016/0022-1694(94)90057-4

DUARTE, W. O.; BRITO, J. L. S. Análise temporal do uso da terra e cobertura vegetal do alto curso do rio Uberabinha utilizando imagens do satélite CBERS 2. Anais XII Simpósio Brasileiro de Sensoriamento Remoto, Goiânia, Brasil, 16-21 abril 2005, INPE, p. 2965-2972.

FERREIRA, A. M. Capacidade de autodepuração no médio e baixo cursos do Rio Uberaba, UPGRH-GD8. Dissertação (Mestrado em Engenharia Civil). Faculdade de Engenharia Civil, UFU, $134 \mathrm{p}, 2014$.

IRITANI, M. A. Modelação Matemática Tridimensional para a Proteção das Captações de Água Subterrânea. (Tese de Doutoramento), Instituto de Geociências, USP, 200 p, 1998.

NASH, J.E.; SUTCLIFF, J. River flow forescasting through conceptual models. Journal of Hidrology, v. 10, n.3, p. 282-290, 1970. https://doi.org/10.1016/0022-1694(70)90255-6

NOBRE, M. E. S.; MARENGO, J. A.; SELUCHI, M. E.; CUARTAS, A.; ALVES, L. M.; MENDIONDO, E. M.; OBREGÓN, G.; SAMPAIO, G. A seca e a crise hídrica de 2014-2015 em São Paulo. Revista USP, v.106, p.31-44, 2015. https://doi.org/10.11606/issn.23169036.v0i106p31-44

PAREDES-ARQUIOLA J.; SOLERA, A.; ÁLVAREZ, J.A.; ELVIRA, N.L. Manual Técnico v1.0 Herramienta EvalHid para la evaluación de recursos hídricos. Universidad Politécnica de Valencia, Valencia, 2011.

REBOUÇAS, A.C.; BRAGA, B.; TUNDISI, J.G. Águas doces no Brasil: capital ecológico, uso e conservação. São Paulo, Acad. Bras. Cien./IEA-USP. 717 p, 1999.

SALLA, M. R.; PAREDES-ARQUiOLA J.; SOleRA, A.; ÁlVAREZ, J. A.; PEREIRA, C. E.; ALAMY FILHO, J. E.; OLIVEIRA, A. L. de. Sistema de Suporte à Decisão em Recursos Hídricos na Bacia Hidrográfica do Rio Uberabinha, Minas Gerais. Revista Brasileira de Recursos Hídricos, Porto Alegre, v. 19, n. 1, p. 189-204. 2014a. https://doi.org/10.21168/rbrh.v19n1.p189-204

SALLA, M. R. Herramienta AQUATOOL en Brasil. Posibles cuestiones del usuário principiante. In: Solera, A.; Paredes-Arquiola, J.; Álvarez, J. A.; Monzonís, M. P. (Org.). Aplicaciones de Sistemas Soporte a la Decisión en Planificación y Gestión Integradas de Cuencas Hidrográficas. 1 ed. Barcelona: Marcombo, v. 1, p. 5-18. 2014b.

SALLA, M. R.; PAREDES-ARQUIOLA J.; ELVIRA, N. L; ALAMY FILHO, J. E.; COSTA, E. S. Aplicação da ferramenta EvalHid para calibração de parâmetros e simulação de vazões no alto curso do rio Araguari, Minas Gerais. Revista Brasileira de Recursos Hídricos, Porto Alegre, v. 19, n.1. p. 189-204. 2015. https://doi.org/10.21168/rbrh.v20n1.p276-285 
SANTOS, M. G. B.; CRUZ, G. D. D.; GOMES, M. M.; SOUTO, R. M. G.; FUSCONI, R.; ROSSI, D. A.; PAVANIN, L. A. Qualidade da água do Rio Uberabinha - o que mudou nos últimos 11 anos? Anais do 3o Congresso Internacional RESAG. Disponível em: http://www.resag.org.br/congressoresag2017/anais/trabalhos/aprovado. Acesso em 11 de out. 2018.

TUCCI, C.E.M. Hidrologia: Ciência e Aplicação. 3a ed., Org. por ABRH, ed. UFRGS, Porto Alegre RS, pp. 253-289, 2004.

Recebido em: 04/07/2018

Aceito para publicação em: 21/11/2018 
Modelagem da recarga hídrica de águas subterrâneas da bacia do rio Uberabinha - Uberlândia - MG
Eleonora Henriques Amorim de Jesus Michele Paula Da Silva Karina do Valle Marques

Apêndice 1

Planilha elaborada no Excel para se obter dados de Vazão simulada, vazão observada e $F_{\text {médio }}$ durante a calibração.

\begin{tabular}{|l|l|l|l|l|}
\hline MÊS/ANO & $\begin{array}{l}\text { SIMULADO } \\
\text { (hm } 3 \text { /mês) }\end{array}$ & $\begin{array}{l}\text { OBSERVADOS } \\
\text { (hm3/mes) }\end{array}$ & $\begin{array}{l}\text { (SIMULADO } \\
\text { OBSERVADO) }\end{array}$ & $\begin{array}{l}\text { (OBSERVADO } \\
\text { MED } \\
\text { OBSERVADO) }\end{array}$ \\
\hline jan/05 & 1.3788 & 3.25568 & 3.522686884 & 482.9360889 \\
\hline fev/05 & & & & \\
\hline mar/05 & 4.3450 & 6.25376 & 3.643550723 & 360.1541183 \\
\hline abr/05 & 5.3896 & 7.34816 & 3.835876199 & 319.813381 \\
\hline mai/05 & 6.2702 & 8.95264 & 7.195725228 & 265.0008564 \\
\hline jun/05 & 7.0123 & 9.85312 & 8.070334482 & 236.4941685 \\
\hline jul/05 & 7.6377 & 10.26528 & 6.904107704 & 223.9873489 \\
\hline ago/05 & 8.1647 & 13.16576 & 25.0102911 & 145.5817656 \\
\hline set/05 & 8.6088 & 19.41408 & 116.7547648 & 33.84222303 \\
\hline out/05 & 8.9828 & 12.15648 & 10.07203075 & 170.9558054 \\
\hline nov/05 & 9.2979 & 19.77792 & 109.8308721 & 29.74139192 \\
\hline dez/05 & 9.5632 & 16.14688 & 43.34471911 & 82.53008251 \\
\hline jan/06 & 27.8078 & 30.76704 & 8.756817223 & 30.64234813 \\
\hline fev/06 & 26.5117 & 36.59904 & 101.7534548 & 129.2212635 \\
\hline mar/06 & 25.4182 & 46.31904 & 436.8448512 & 444.6848958 \\
\hline abr/06 & 24.4955 & 49.19616 & 610.1242734 & 574.3055568 \\
\hline mai/06 & 23.7168 & 36.00288 & 150.9489703 & 116.0229093 \\
\hline jun/06 & 23.0595 & 24.93504 & 3.517722603 & 0.087880764 \\
\hline jul/06 & 22.5046 & 21.48768 & 1.034159759 & 14.0160901 \\
\hline ago/06 & 22.0361 & 18.42912 & 13.01032951 & 46.27219543 \\
\hline set/06 & 21.6404 & 34.44672 & 164.0017291 & 84.92052111 \\
\hline out/06 & 21.3061 & 32.90176 & 134.4592636 & 58.83308944 \\
\hline nov/06 & 21.0236 & 27.5456 & 42.53681764 & 5.355119445 \\
\hline dez/06 & 20.7847 & 32.4288 & 135.5850191 & 51.80131587 \\
\hline jan/07 & 59.8199 & 79.15744 & 373.9395728 & 2908.008418 \\
\hline fev/07 & 52.9320 & 12.15278 & 1662.947192 & 171.0526323 \\
\hline mar/07 & 47.1235 & 43.83072 & 10.84208967 & 345.9314719 \\
\hline abr/07 & 42.2250 & 70.17344 & 781.1158593 & 2019.779149 \\
\hline mai/07 & 38.0940 & 33.04288 & 25.51337684 & 61.01786218 \\
\hline
\end{tabular}




\begin{tabular}{|c|c|c|c|c|}
\hline jun/07 & | 34.6100 & 24.4944 & | 102.3261793 & | 0.543297097 \\
\hline jul/07 & 31.6718 & 19.5136 & 147.8215714 & 32.69423059 \\
\hline ago/07 & 29.1937 & 19.41408 & 95.64014701 & 33.84222303 \\
\hline set/07 & 27.1035 & 15.88896 & 125.766161 & 87.28280886 \\
\hline out $/ 07$ & 25.3405 & 10.80704 & 211.2221369 & 208.0646683 \\
\hline nov/07 & 23.8534 & 37.24704 & 179.3894839 & 144.3735163 \\
\hline dez/07 & 22.5989 & 44.50464 & 479.8612476 & 371.4544305 \\
\hline jan/08 & 64.3602 & 36.13248 & 796.8064775 & 118.8316506 \\
\hline fev/08 & 57.0295 & 69.25824 & 149.5421352 & 1938.354989 \\
\hline $\mathrm{mar} / 08$ & 50.8474 & 79.88544 & 843.2052329 & 2987.05459 \\
\hline$a b r / 08$ & 45.6340 & 74.83104 & 852.4675146 & 2460.115668 \\
\hline mai/08 & 41.2373 & 39.34656 & 3.574882482 & 199.2352886 \\
\hline jun/08 & 37.5293 & 30.63744 & 47.49780319 & 29.22432893 \\
\hline jul/08 & 34.4020 & 27.06048 & 53.89864224 & 3.345215764 \\
\hline ago/08 & 31.7645 & 22.1616 & 92.215403 & 9.424205572 \\
\hline set/08 & 29.5398 & 20.4768 & 82.13871512 & 22.60704751 \\
\hline out/08 & 27.6634 & 25.58304 & 4.327824312 & 0.123589583 \\
\hline nov/08 & 26.0805 & 27.83808 & 3.089008983 & 6.794327595 \\
\hline dez/08 & 24.7452 & \begin{tabular}{|l|}
43.88256 \\
\end{tabular} & 366.2373074 & 347.8625278 \\
\hline jan/09 & 70.6601 & 65.42208 & 27.4369885 & 1615.283774 \\
\hline \multicolumn{5}{|l|}{ fev/09 } \\
\hline $\mathrm{mar} / 09$ & 54.3430 & 50.62176 & 13.84764433 & 644.6659681 \\
\hline $\mathrm{abr} / 09$ & 48.0479 & \begin{tabular}{|l|}
49.29984 \\
\end{tabular} & 1.567265013 & 579.285621 \\
\hline mai/09 & 42.7393 & \begin{tabular}{|l|}
34.05888 \\
\end{tabular} & 75.34963992 & 77.92286896 \\
\hline jun/09 & 38.2624 & 32.24448 & 36.21585158 & 49.18207224 \\
\hline jul/09 & 34.4870 & 29.78208 & 22.13594076 & 20.70789757 \\
\hline ago/09 & 31.3029 & 24.624 & 44.60785105 & 0.369040332 \\
\hline \multicolumn{5}{|l|}{ set/09 } \\
\hline out/09 & 26.3527 & 27.39744 & 1.091425006 & 4.691352836 \\
\hline nov/09 & 24.4425 & 38.43936 & 195.9124496 & 174.4479119 \\
\hline dez/09 & 22.8312 & 74.05344 & 2623.712875 & 2383.583105 \\
\hline jan/10 & 65.1039 & 58.68288 & 41.22904373 & 1118.9957 \\
\hline $\mathrm{fev} / 10$ & 56.8771 & 29.26368 & 762.5023627 & 16.2585812 \\
\hline $\mathrm{mar} / 10$ & 49.9397 & 65.13696 & 230.9567727 & 1592.446783 \\
\hline$a b r / 10$ & 44.0895 & 35.01792 & 82.29269356 & 95.77427284 \\
\hline mai/10 & 39.1559 & 47.9568 & 77.4550362 & 516.4398555 \\
\hline
\end{tabular}




\begin{tabular}{|c|c|c|c|c|}
\hline jun/10 & | 34.9955 & 17.85888 & | 293.6623079 & | 54.35533249 \\
\hline $\mathrm{jul} / 10$ & 31.4868 & 16.40736 & 227.3895072 & 77.86521553 \\
\hline ago/10 & 28.5278 & 67.664 & 1531.643619 & 1800.518168 \\
\hline set/10 & 26.0322 & 8.52768 & 306.4093739 & 279.0171649 \\
\hline out/10 & 23.9275 & 28.9008 & 24.73376358 & 13.46385863 \\
\hline nov/10 & 22.1523 & 29.13344 & 48.73634058 & 15.225238 \\
\hline dez/10 & 20.6550 & 53.16192 & 1056.701189 & 780.1090932 \\
\hline jan/11 & 59.1052 & 67.99936 & 79.10567166 & 1829.09097 \\
\hline fev/11 & 52.1219 & 49.7872 & 5.450687769 & 602.9830459 \\
\hline $\mathrm{mar} / 11$ & 46.2328 & 81.6688 & 1255.707694 & 3185.17031 \\
\hline$a b r / 11$ & 41.2666 & 74.08448 & 1077.016388 & 2386.614935 \\
\hline mai/11 & 37.0784 & 42.98944 & 34.94084824 & 315.3448983 \\
\hline jun/11 & 33.5463 & 31.25952 & 5.229260623 & 36.33718307 \\
\hline $\mathrm{jul} / 11$ & 30.5674 & 22.05792 & 72.41193032 & 10.07152686 \\
\hline ago/11 & 28.0551 & 21.9024 & 37.85588819 & 11.08281958 \\
\hline set/11 & 25.9362 & 14.28192 & 135.8213681 & 119.8930153 \\
\hline out/11 & 24.1489 & 28.20096 & 16.41906979 & 8.817770498 \\
\hline nov/11 & 22.6414 & 35.58816 & 167.6194109 & 107.2606777 \\
\hline $\mathrm{dez} / 11$ & 21.3697 & 45.016 & 559.1487607 & 391.4269586 \\
\hline jan/12 & 61.5216 & \begin{tabular}{|l|}
75.2768 \\
\end{tabular} & 189.2066422 & 2504.533363 \\
\hline fev/12 & 54.1361 & 41.83488 & 151.318943 & 275.6726625 \\
\hline $\operatorname{mar} / 12$ & 47.9079 & 38.51712 & 88.18707101 & 176.5080469 \\
\hline$a b r / 12$ & 42.6557 & 44.40096 & 3.045943236 & 367.468699 \\
\hline mai/12 & 38.2264 & 37.09152 & 1.287945935 & 140.6603852 \\
\hline jun/12 & 34.4910 & 31.07808 & 11.64805742 & 34.18265089 \\
\hline $\mathrm{jul} / 12$ & 31.3407 & 21.20256 & 102.782576 & 16.23225196 \\
\hline ago/12 & 28.6839 & 16.4592 & 149.4421334 & 76.95301744 \\
\hline set/12 & 26.4430 & 15.96672 & 109.7526504 & 85.83590569 \\
\hline out/12 & 24.5530 & 22.70592 & 3.411637335 & 6.378488161 \\
\hline nov/12 & 22.9588 & 44.16768 & 4449.817874 & 358.5794092 \\
\hline dez/12 & 21.6140 & 40.72032 & 365.0515609 & 239.9039508 \\
\hline jan/13 & 62.3363 & 42.84576 & 379.8824289 & 310.2626169 \\
\hline \multicolumn{5}{|l|}{$\mathrm{fev} / 13$} \\
\hline $\mathrm{mar} / 13$ & 48.1524 & 31.98528 & 261.3759417 & 45.61372125 \\
\hline$a b r / 13$ & 42.6802 & \begin{tabular}{|l|}
37.94688 \\
\end{tabular} & 22.4047522 & 161.6812217 \\
\hline mai/13 & 38.0655 & 21.35808 & 279.1386107 & 15.003281 \\
\hline
\end{tabular}




\begin{tabular}{|l|l|l|l|l|} 
jun/13 & 34.1738 & 42.57472 & 70.57529627 & 300.7877344 \\
\hline jul/13 & 30.8918 & 22.6816 & 67.40672275 & 6.501923197 \\
\hline ago/13 & 28.1238 & 13.98592 & 199.8794551 & 126.4627749 \\
\hline set/13 & 25.7893 & 28.81952 & 9.182144058 & 12.87398153 \\
\hline out/13 & 23.8204 & 22.31712 & 2.259745403 & 8.493534422 \\
\hline nov/13 & 22.1596 & 25.29792 & 9.848811331 & 0.004413357 \\
\hline dez/13 & & & & \\
\hline jan/14 & & & & \\
\hline fev/14 & 51.9519 & 31.1040 & 434.6357217 & 34.48641012 \\
\hline mar/14 & 45.1676 & 25.84224 & 373.4683323 & 0.37301935 \\
\hline abr/14 & & & & \\
\hline mai/14 & 34.6221 & 14.85216 & 390.8491749 & 107.7304269 \\
\hline jun/14 & & & & \\
\hline jul/14 & 27.1227 & 26.4384 & 0.468331851 & 1.456639234 \\
\hline ago/14 & 24.2294 & 17.6272 & 43.58916225 & 57.82517924 \\
\hline set/14 & 21.7894 & 18.67648 & 9.690015019 & 42.96811545 \\
\hline out/14 & 19.7315 & 12.76512 & 48.53092205 & 155.4103037 \\
\hline nov/14 & 17.9960 & 19.70592 & 2.923789327 & 30.53188955 \\
\hline dez/14 & 16.5323 & 50.25888 & 1137.484811 & 626.3704054 \\
\hline Somatório & & $\mathbf{3 7 5 9 . 9 6 6 2 1 8}$ & $\mathbf{2 6 1 7 3 . 0 0 8 4 5}$ & 45656.66796 \\
\hline & & $\begin{array}{l}\text { OED } \\
\text { oBSERVADO }\end{array}$ & & \\
\hline & & 25.2314869 & & \\
\hline & & & \\
\hline
\end{tabular}

